\title{
Width and Clustering of Ion-Conducting Channels in Fuel Cell Mem- branes are Insensitive to the Length of Ion Tethers
}

\author{
Adam Barnett, Jibao Lu, Valeria Molinero* \\ Department of Chemistry, The University of Utah, 315 South 1400 East, Salt Lake City, Utah 84112-0850, United States \\ * corresponding author, email: Valeria.Molinero@utah.edu
}

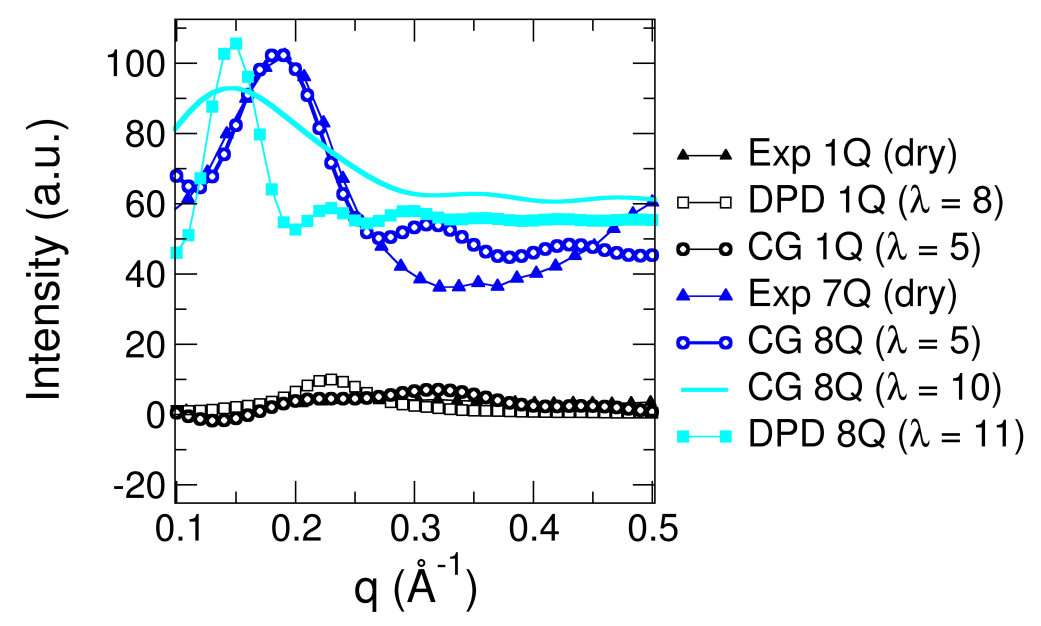

Figure S1. Comparison of the structure factor calculated of membranes in experiments (EXP) and simulations with the high-resolution coarse-grained model of this work $(\mathrm{CG})$ and dissipative particle dynamics (DPD) by Ming-Tsung Lee in ref. 2 Also included are our structure factor at $\lambda=10$ for the $7 \mathrm{Q}$ membrane to compare with the water content of Lee. The structure factor of the lamellar structure more closely resembles the ionomer peaks of PFOS and other short chain, micellar PEM.1-2 We have also included our 8Q membrane at a $\lambda=10$ water content in Figure 5 to show how the ionomer peak shifts and broadens at higher water contents due to widening water pores (Supp. Fig. S3). This broadening matching the experimental results of Nafion. ${ }^{3}$

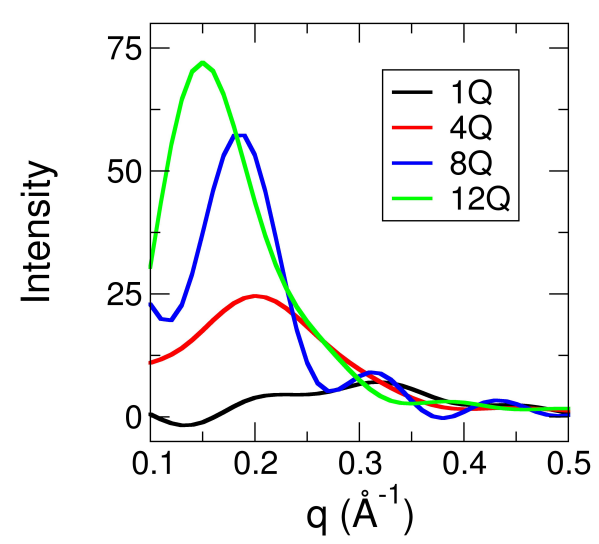

Figure S2. Development and downshift of the ionomer peak in the structure factor of the NQ membranes. 


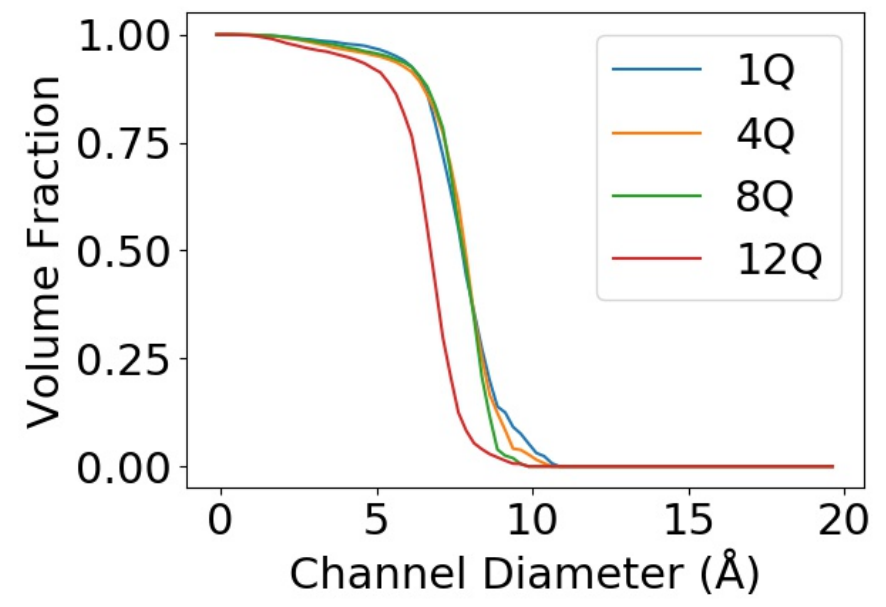

Figure S3. Pore width distributions of the NQ membrane with water content $\lambda=5$. Distribution indicate volume fraction of the hydrophilic channels that can be explored by a probe molecule with the width of water. The limiting pore diameter (first shoulder) is located around 6-7 Angstroms, the median pore size (volume fraction 0.5) lies at about 7-8 Angstroms, and the largest pores (final tails) in the membranes lie somewhere around $1 \mathrm{~nm}$.

\section{References}

(1) Berrod, Q.; Lyonnard, S.; Guillermo, A.; Ollivier, J.; Frick, B.; Manseri, A.; Améduri, B.; Gébel, G., Nanostructure and Transport Properties of Proton Conducting Self-Assembled Perfluorinated Surfactants: A Bottom-up Approach toward Pfsa Fuel Cell Membranes. Macromolecules 2015, 48, 6166-6176.

(2) Lee, M.-T., Exploring Side-Chain Designs for Enhanced Ion Conductivity of Anion-Exchange Membranes by Mesoscale Simulations. The Journal of Physical Chemistry C 2019, 123, 10802-10815.

(3) Perrin, J.-C.; Lyonnard, S.; Volino, F., Quasielastic Neutron Scattering Study of Water Dynamics in Hydrated Nafion Membranes. The Journal of Physical Chemistry C 2007, 111, 3393-3404. 